\title{
Interactive comment on "Reviews and syntheses: Turning the challenges of partitioning ecosystem evaporation and transpiration into opportunities" by Paul C. Stoy et al.
}

\author{
Paul C. Stoy et al. \\ telmad@bgc-jena.mpg.de \\ Received and published: 24 May 2019
}

We thank Dr. Wei for insightful comments and we hope that we have addressed them all adequately. In the supplement you find all your comments and our responses listed.

Please also note the supplement to this comment:

https://www.biogeosciences-discuss.net/bg-2019-85/bg-2019-85-AC3-supplement.pdf 